\section{EL LOBO DE FRESA Y EL BOSQUE DE CHOCOLATE. SENEL PAZ Y SUS VARIACIONES CINEMATOGRÁFICAS}

\author{
Jean-Claude Seguin \\ Université Lumière, Lyon 2 \\ jean-claude.seguin@univ-lyon2.fr
}

\section{THE WOLF OF STRAWBERRY AND THE FOREST OF CHOCOLATE. SENEL PAZ AND HIS CINEMATOGRAPHIC VARIATIONS}

RESUMEN: Desde su breve cuento "No le digas que la quieres" hasta su última obra En el cielo con diamantes (2007), Senel Paz no ha dejado de recorrer un mundo poblado de personajes que de un cuento a una película y de un film a una novela siempre están en devenir. David, Miguel, Diego, Vivian, Nancy, Ismael, etc. no dejan de resurgir tanto en Una novia para David, como en el cuento El Lobo, el bosque y el hombre nuevo que dio origen a Fresa y chocolate. Esas figuras constantemente en evolución se van amoldando a los relatos tanto escritos como filmados. Las fronteras entre cuento y película tienden asi a borrarse dejando un lugar para formas mixtas de personajes, a veces sin cuerpo -las figuras de papel y tinta- a veces fantasmas -las siluetas de la pantalla cinematográfica. Estos deslices progresivos e incesantes de los deseos se abren continuamente hacia territorios inconclusos, porosos y continuamente abiertos.

PALABRAS CLAVE: Senel Paz; Una novia para David; El lobo, el bosque y el Hombre Nuevo; Fresa y Chocolate; En el cielo con Diamantes; Cine cubano.

A Tim Burton, a Charlie y a su chocolatería

"A nadie he amado más que a él" Stefan Zweig, La Confusión de los sentimientos

se intentan desvelar en este ensayo y que llevan a considerar el auténtico rizoma que constituye buena parte de la actividad creadora -la literatura, por supuesto, pero también de manera muy significativa el cine-, en un entramado donde los textos se van interpelando a modo de diálogo creativo que pone en tela de juicio la unidad de la obra, su forma canónica y su intangibilidad.

\section{Gestaciones}

La escritura se inscribe así en un fluido que, en el caso de Senel Paz, extrema las formas de independencia de los 
elementos narrativos, las figuras, las historias, los sentimientos, las diégesis, que acabarán por convertirse en estructuras en perpetuo cambio, en proceso, si por ello se entiende una creación incoativa. El cuento El lobo, el bosque y el hombre nuevo no nace de la nada sino que va recogiendo unos cuantos elementos ya presentes en la obra de Senel Paz. Desde sus comienzos, el escritor cubano va instalando una serie de elementos que prefiguran -en el sentido que le da a esta palabra Erich Auerbach-, a ciertos personajes del cuento y anticipan algunas situaciones. En este sentido, la historia de Pedrito, en el breve cuento No le digas que la quieres (1981) podría constituir un germen para la producción posterior y la inspiración del episodio inicial de Fresa y chocolate, ausente en El lobo, el bosque y el hombre nuevo, una forma de introito que volveremos a analizar. Sin embargo, el texto ofrece muchos elementos que preludian otros aspectos fundamentales y no solo factuales de la película de Tomás Gutiérrez Alea y Juan Carlos Tabío como el tratamiento del trasfondo social-histórico cubano que, en No le digas que la quieres, remite a una forma de observar la realidad isleña algo desplazada pues nunca llega a constituirse en crítica abierta. En el relato, Arnaldo es quien ofrece ese punto de vista:

¿Tú sabes qué pasa? Que ahora no es como antes. Antes cumplias los trece o catorce años y tu papá o un hermano tuyo te llevaba a un prostíbulo y ya, empezabas. Ahora no porque estamos en el socialismo y eso era una lacra social y, claro, hubo que eliminarla. Pero ¿Sabes qué? Que nosotros nos quedamos en el aire. Debieron haber dejado un prostíbulo, uno solito, pedagógico, para nosotros los becados, ¿no crees? (Paz, 2003, 143).

Se privilegia así una forma incidental de comentar la realidad social y política que caracteriza el tono desenfadado de la escritura de Senel Paz, aludiendo como si nada, a aspectos discutibles de la Revolución, background presente asimismo en la evocación de la figura del Che durante los días en que se va a anunciar su muerte, $y$, de manera más íntima, en la vida de los becarios en La Habana. En ello se perciben ya algunas constantes del universo del novelista que, hasta En el cielo con diamantes, sigue siendo el mismo. De igual modo, la forma de organizar los personajes en forma de tríada -Arnaldo, Vivian y el narrador Pedrito- funciona como una estructura básica de los diferentes relatos que se van a desvelar por completo en la última novela de Senel Paz bajo la siguiente forma conceptual: Yo (narrador)/Amigo/Novia, un esquema esencial que encuentra en Fresa y chocolate su actualización más acabada y compleja. Por lo demás, No le digas que la quieres encierra las principales formas de la escritura del guajiro: un juego constante sobre el narrador y los puntos de vista, interpolaciones de relatos, la erotización de las situaciones, el deseo, etc. Podríamos decir que, en cierto modo, todo el material que luego se irá desarrollando de una obra a una película y de una película y otra, no es más que el ir y venir de los mismos personajes profundizados.

No le digas que la quieres no es la única obra que se vislumbra en la gestación de El lobo, el bosque y el hombre nuevo. A ella hay que añadir la película Una novia para David de Orlando Rojas, primer guión cinematográfico de Senel Paz, y precedente esencial para comprender el origen del texto, cuyo director desembocó en el cine tras desarrollar una larga carrera como crítico cinematográfico, una colaboración fructuosa que tendría su continuación en Papeles secundarios, relacionada asimismo con Fresa y chocolate ${ }^{3}$. Aquí aparece ya elaborada la estructura básica: David, un joven guajiro; Miguel, un amigo seductor; Olga/Ofelia, la(s) novia(s) y la beca (contexto universitario y generacional). El triángulo David/amigo/novia continuará siendo idéntico hasta la última novela de Senel Paz, si bien la reelaboración cinematográfica enriquece y matiza las relaciones entre ambos. Por una parte, si bien los personajes ya están "en su sitio", algunos de los actores de Una novia para David van a figurar también en el reparto de Fresa y chocolate, en su mayoría estudiantes que no tenían en aquel momento ninguna experiencia cinematográfica. El futuro David de la película de Tomás Gutiérrez Alea, Vladimir Cruz, interviene ya como figurante en Una novia para David, y, sobre todo, Miguel es interpretado por Francisco Gattorno, futuro actor de soap mexicanos. Como es sabido, la figura de Miguel en la película de Orlando Rojas es la de un seductor muy preocupado por su aspecto físico, elemento que se volverá mucho más presente en Fresa y chocolate en la que aparece como un personaje de indudable ambigüedad. En este sentido, resulta de interés contraponer dos secuencias de Una novia para David en las cuales Miguel y David están solos y juntos: una escena en la ducha de la beca y un diálogo íntimo entre los dos personajes, en un ambiente nocturno que remite a intimidades masculinas cuyos referentes parecen estar en la figura del James Dean -uno de los ídolos de Miguel- de Al este del Edén o de Rebelde sin causa. Aunque en ningún momento se sugiere ningún tipo de deseo homosexual, la tonalidad homófila 


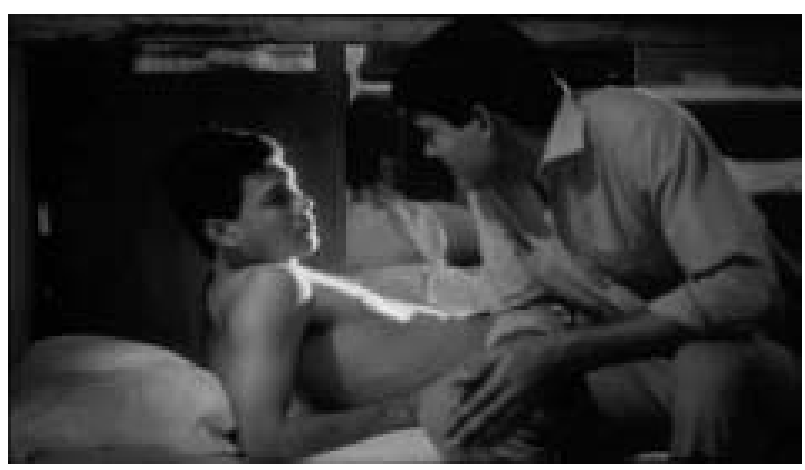

Figura 1. "David y Miguel en el dormitorio". Orlando Rojas, Una novia para David (1985).

de ambas escenas no deja lugar a dudas, privilegiando una configuración nueva de lo masculino, que hace evolucionar los límites del gender.

En el planteamiento del personaje de Miguel en El lobo, el bosque, y el hombre nuevo y Fresa y chocolate, se va a producir un progresivo desplazamiento hacia formas de afectividad, de celos y de deseos turbios que convierten a Miguel en un homófobo que no consigue mantener su estatuto de seductor como lo hiciera en Una novia para David y que no tolera que su rol de "amigo" lo vaya ocupando progresiva y definitivamente un homosexual como Diego. En cuanto a David, el personaje inicial es todavía un joven bastante inseguro de sí mismo y de los demás, sus rasgos de guajiro están todavía muy presentes, y se muestra en un principio como un novato que terminará por asumir sus propios deseos, por cierto muy "razonables", prefiriendo a la guapa y seductora Olga, a la gorda Ofelia, ideológicamente irreprochable. Su evolución hacia el miembro de las juventudes comunistas que aparece en la novela corta de Senel Paz se puede ya presentir. En cuanto a los personajes femeninos no revisten la misma importancia a pesar de constituir una "meta" para David, un objetivo afectivo, y se irán modificando varias veces hasta En el cielo con diamantes, sin llegar nunca a constituir el polo central de los relatos, ni siquiera llegar a cierta forma de estabilidad. La figura femenina está siempre como desdoblada entre "la virgen" y "la prostituta", escisión prefigurada en Una novia para David.

Dentro de lo que podriamos llamar el territorio femenino que se va construyendo y elaborando antes de la publica-

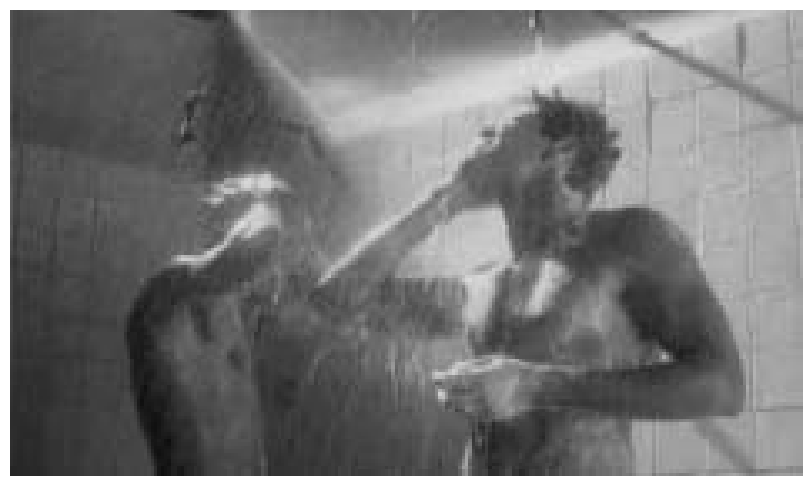

Figura 2. "David y Miguel en la ducha". Orlando Rojas, Una novia para David (1985).

ción de El lobo, el bosque, y el hombre nuevo, la gestación de Vivian y de Nancy va a ser particularmente larga. Es cierto que Vivian ya está presente en el cuento No le digas que la quieres, pero su personaje insulso $y$, al fin y al cabo, estabilizador, no permite muchos desarrollos; por su parte, la militancia de Ofelia -otra figura de "la novia"- se diluirá y desaparecerá por completo. El otro polo femenino lo ocupa el personaje de "la prostituta" que Olga, podría prefigurar únicamente en ciertos aspectos. No obstante, la aportación más significativa para el personaje de Nancy en Fresa y chocolate la encontramos en el largometraje de Gerardo Chijona, Adorables mentiras (1991), de cuyo guión es coautor Senel Paz. En esta película dedicada a los juegos del amor y de las mentiras, el escritor crea el personaje de Nancy ya interpretado por Mirta Ibarra en un relato que, por otra parte, está bastante alejado de Fresa y chocolate. Nancy no es un personaje principal de Adorables mentiras del que habla el director en estos términos:

Estoy encariñado con todos los personajes. El de Nancy es el más contradictorio, el más trágico, el más desgarrador. Rechazada no sólo en su trabajo, no encuentra el verdadero camino del afecto, no tiene religión, ni tan siquiera gas para poder suicidarse. Diría que Nancy es un personaje sacado de los Hermanos Marx. Ella dice verdades que mucha gente no quisiera oír (García Borrero, 2001, 39).

Estos breves comentarios permiten, sin embargo, dibujar la figura de quien será la Nancy de Fresa y chocolate, un personaje hiperemotivo, lleno de contradicciones, dispuesto a todo por conseguir el amor, matizado y enriquecido en la película de Tomás Gutiérrez Alea.

ARBOR Vol. 187748 marzo-abril [2011] 325-335 ISSN: 0210-1963 
El conjunto de estas prefiguraciones preparan la base sobre la cual se van a desarrollar tanto el cuento de Senel Paz como la película de Titón, obras ambas que, aunque con diferentes significados, beben en la misma fuente creativa.

\section{EL LOBo, el bosaue y el hombre nUeVo (1990)}

En el proceso que va a conducir hasta la película y más allá a la novela En el cielo con diamantes, resulta delicado limitar la "adaptación" cinematográfica al único cuento de Senel Paz. Convendría, por el contrario, utilizar la palabra "creación" que permite incluir así las diferentes facetas de esta "saga" para considerar la novela breve de Senel Paz como el término de un recorrido que había empezado casi diez años antes con No le digas que la quieres.

Sin menospreciar lo que puede ser su producción literaria o cinematográfica, no cabe la menor duda de que El lobo, el bosque y el hombre nuevo (1990) es la obra más conocida de Senel Paz, la que le dio una fama internacional. Este cuento que narra el despertar a la vida de un joven provinciano es, además, una reflexión política desde la Cuba de los primeros noventa y, según algunos críticos, el primer escrito postmoderno que se dio en la isla, opinión a la cual Senel Paz responde:

Me considero un escritor primario e instintivo, aunque eso no quiere decir que me mantenga de espaldas a las tendencias más actuales de la literatura. No reelaboro teóricamente lo que escribo, ni siquiera como profesor de Dramaturgia me gusta encasillarme en este mecanismo de pensamiento conceptual. Me salen las cosas sin necesidad de pincharlas para descubrir el misterio. El lobo... ciertamente posee una serie de caracteristicas que no asumo de forma consciente ni porque esté de moda. Se encuentra en el ambiente como expresión de la naturaleza del escritor de estos tiempos, se convierte en una necesidad. Uno se inserta sin proponérselo (Valdés Lizano, 2007).

Las características formales del cuento, dejando de lado la historia en sí, lo convierten en un relato que no deja de explorar diferentes tiempos y estilos así como la recurrencia a ciertos procedimientos expresivos:
1. La presencia de un narrador en primera persona, de tipo homodiegético, que es el protagonista del cuento, aunque surgen a veces algunos elementos en tercera persona.

2. El relato está escrito en pasado y la acción se podría situar a finales de los años 60.

3. La estructura se encierra en una larga analepsis que incluye la práctica totalidad del cuento.

4. Aunque domina el estilo indirecto, también integra muchos elementos de estilo indirecto libre.

Algunas de estas características pertenecen a la escritura como la estructura temporal, el narrador -en el cine habría que hablar de ocularizador-, etc., pero se llegan a trasponer del texto a la imagen, aunque se van a operar una serie de cambios importantes como lo muestran los diferentes guiones.

\section{FRESA Y CHOCOLATE: LOS GUIONES Y LA PELÍCULA}

En la adaptación de un texto literario, además de lo irreductible de la escritura con relación al cine, se pueden integrar una serie de modificaciones que ya pertenecen al relato en sí. La manera de considerar el proceso de adaptación por parte del "adaptado" y del "adaptador" es bastante reveladora de posturas personales. Gracias a dos entrevistas, disponemos de las dos versiones sobre la adaptación y el guión de la película. Tomás Gutiérrez Alea cuenta cómo se originó la idea de transformar el cuento El lobo, el bosque y el hombre nuevo en un guión primero, y en una película después:

Cuando Senel me entregó el manuscrito de su cuento $E I$ lobo, el bosque y el hombre nuevo, para ver qué me parecia, ya venía con la secreta intención de seducirme, de atraparme y obligarme a decirle, como le dije: aquí hay una película y me encantaría hacerla; te propongo que empecemos enseguida a trabajar en el guión... Era inevitable, pues desde la primera lectura se revelaba como una historia necesaria, como algo que seguramente todos queriamos escuchar o decir $(1991,119)$.

La versión de la génesis de la colaboración con Titón es bastante similar en ambos casos, como se puede puede apreciar en la versión de Senel Paz: 
Siempre me pareció que del cuento podía salir una película. Pero no me gusta ser yo quien le proponga a un director trabajar con él, sino lo contrario, que sea él quien me lo pida, porque en ese caso lo más probable es que él ya sepa lo que quiere y traiga una propuesta concreta. El escritor tiene más facilidad que el cineasta, creo yo, para meterse en el pellejo de otro y tratar de pensar con su cabeza. Me parece que somos más dúctiles y flexibles. En cualquier caso, no quisiera tener que lidiar con esos directores que se ponen a pedirle cosas a uno sin saber ellos mismos qué es lo que realmente quieren. En este caso, le mandé el cuento a Titón -que es como le decimos a Gutiérrez Alea- con la aviesa intención de interesarlo para el futuro. Titón es un director a quien admiro mucho y con el que tenía ganas de trabajar. Mis tres guiones anteriores habían sido escritos para directores debutantes ${ }^{4}$, y ahora yo quería trabajar con alguien de experiencia, del que también pudiera aprender. Tuve suerte. Dos horas después de haber recibido el cuento, Titón me llamó para proponerme que lo adaptara al cine, y yo, haciéndome el bobo, dejé que me convenciera, como si ya no hubiera estado convencido (García Márquez, 1998, 158-159).

Entre el cuento escrito por Senel Paz y la versión definitiva del guión hubo, de hecho, diez etapas diferentes. Esta lenta y difícil gestación se puede explicar, primero, por la dificultad para traducir en lenguaje cinematográfico el cuento, sobre todo, por cuanto la escritura del cubano -lo mismo ocurre con su última novela En el cielo con diamantes- va navegando constantemente de una situación a otra ofreciendo una gran flexibilidad narrativa que hace a veces perderse en este constante juego entre narrador(es), tiempo y espacio.

La elaboración del guión fue, por consiguiente, una etapa bastante compleja pero esencial para comprender de qué forma se llega del texto a la imagen, siendo el guión un texto escrito pensado para la pantalla, una forma de visualizar un texto escrito. Gracias al artículo de Gilda Santana que trabajó directamente en las modificaciones del mismo, tenemos una visión precisa del proceso detallado que condujo a la versión definitiva. Se puede considerar una primera etapa marcada por los cinco primeros esbozos en la que se conservan elementos que seguían planteando problemas. El primero era la construcción retrospectiva -"la historia contada era demasiado abarcadera y no dejaba lugar para la del David actual, un escritor feliz" (Santana, 1994, 136). También ofrecian dificultades los textos en off y la introspección de David - "En las primeras versiones abundaban los textos en off de David. El personaje reflexionaba, imaginaba escenas, recordaba, y hasta llegaba a recordar y a imaginar dentro de otro recuerdo" (Santana, 1994, 137). Seguía además pendiente el final de la película que no llegaba a convencer realmente - "La primera versión concluía con el David actual, que después de terminar de escribir, se iba a la heladería a tomar un helado de fresa. A partir de la segunda y hasta la quinta el final fue la escena donde ellos vuelven a Coppelia y al reproche de Diego: 'lástima que no seas maricón', David le respondía con un 'nadie es perfecto'. Era una cita de la película Algunos prefieren quemarse (en España Con faldas y a lo loco) de la que Diego, claro está, era un admirador. Era también un buen final. Pero no era, definitivamente, el final para esta película" (Santana, 1994, 137).

Como se puede apreciar en las críticas de Gilda Santana, la adaptación planteaba problemas por la conservación de demasiados elementos "literarios" que entorpecian el flujo de la película. La sexta versión del guión marcó una etapa definitiva en la elaboración de proyecto porque se abandonaba lo esencial de lo que indicaba Santana. Desaparecieron la estructura retrospectiva general y el personaje de Ismael - "En su lugar quedará Bruno (luego llamado Miguel) y su carácter de extremista y dogmático se convierte en el impulso que necesita David (también dogmático, pero mucho más cauto y humano) para tomar el camino equivocado de la persecución y de la delación" (Santana, 1994, 137). Además el personaje de Nancy, ya presente en el primer guión, cobró protagonismo. Por fin, se rehízo el final - Nancy y David van a despedir a Diego al aeropuerto- que seguía siendo poco satisfactorio - "Definitivamente tampoco podía ser así. Nancy es una excelente subtrama, pero no es ni con mucho la trama principal. La ida de Diego, que es casi obligado a abandonar su país, y la impotencia y el desgarramiento de David quien, a su pesar, contribuyó con su ignorancia y su cobardía, son el problema principal. No puede haber final color de rosa porque para Diego no habrá ya nunca una segunda posibilidad, como de cierta manera ya tampoco la habrá para David" (Santana, 1994, 137).

Este nuevo guión, ha ido resolviendo uno a uno cuantos problemas presentaba el anterior, pero sin solventar el

ARBOR Vol. 187748 marzo-abril [2011] 325-335 ISSN: 0210-1963 
final incoherente, sólo resuelto por el deseo de Senel Paz de presentar el proyecto al concurso de Festival de Cine, que le obliga a volver sobre el trabajo para encontrarse con el desenlace definitivo, el abrazo entre David y Diego. En aquel momento, el guión tenía por título Enemigo rumor, un homenaje al poemario de Lezama Lima que ganó el premio. Las tres últimas versiones ya no son más que ajustes secundarios en un sinfín de trasvases del texto literario al guión y la película, cuyos pormenores se ponen de manifiesto en diferentes declaraciones del novelista y del director. Así afirmaba Titón:

Después está la estructura, que presenta nuevos problemas cuando se trata de una película de casi dos horas de duración. Una estructura sólida requiere estar muy bien apuntalada. La historia de David y Diego, tal como aparece en el cuento resulta demasiado lineal y concisa y contiene más reflexiones que situaciones dramáticas. Era necesario inventar nuevos elementos para poder decir, a través de situaciones dramáticas, muchas ideas que en el cuento se expresan en reflexiones que hace el personaje (Gutiérrez Alea, 1991, 119-120).

La posición de Gutiérrez Alea fue también la de Senel Paz quien consideró que se tenían que abandonar ciertos

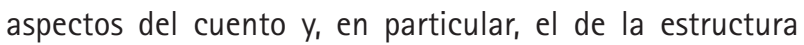
básica; demasiado compleja para una narración cinematográfica:

SENEL. -...El relato está contado en retrospectiva desde el punto de vista de David. En realidad, es un monólogo donde el personaje de Diego no tiene presencia, sino que es referido, filtrado por la conciencia del otro. Diego no tiene voz propia, sino incorporada. Por tanto, yo no me propuse "adaptar" el cuento sino tomar la historia y volver a escribirla, esta vez como guión. No me interesaba en absoluto "respetar" el texto narrativo; lo que me interesaba era descubrir -y salvar- lo que el texto podía tener de cinematográfico. $Y$ tuve que reconocer que David -un personaje tan introspectivo, que toma pocas decisiones, que ejecuta pocas acciones, que prefiere observar y pensar y dejarse arrastrar por sus sentimientos...- un personaje así, desde el punto de vista dramatúrgico, no es muy atractivo que digamos. En la primera versión del guión yo mantenía la idea de la retrospectiva -toda la historia habia ocurrido quince años antes y ahora David la evocaba-, de manera que en el presente veíamos a David convertido en escritor... una manera de decir que, al final, aquella difícil amistad entre él y Diego había fructificado. A Titón le gustaba mucho este enfoque.

Gabriela.- ¿Y por qué lo desecharon?

Senel.- Porque dividía la historia de modo demasiado tajante. Creaba un antes y un después y revelaba demasiado pronto que la amistad había pasado, que ya Diego se habia ido del pais, en fin... La retrospectiva conspiraba contra la expectativa. $Y$ entonces decidi contarla en presente, linealmente (García Márquez, 1998, 162-163).

Estas evoluciones no afectaron, sin embargo, al conjunto del cuento y en la película permanecieron bastantes elementos como ciertos lugares -la heladería Coppelia, la Guarida y algunos de sus decorados y las estatuas, las calles de La Habana, etc.-, algunos de los personajes principales -Diego, David, Vivian y Germán-, unas situaciones como el encuentro con David y el intento de seducción de Diego, el almuerzo lezamiano, la mancha en la camisa, etc. Las similitudes no constituyen lo más significativo, mientras que las diferencias son más reveladoras de la evolución de la narración en la película:

1. Las desapariciones de:
a. Ismael.
b. El relato sobre Casa de muñecas.
c. La primera experiencia sexual de Diego.
d. El texto largo sobre las categorías de "marico- nes" 5 .

2. Las apariciones de:
a. El episodio inicial con Vivian.
b. Los personajes de Nancy y Miguel.

La ausencia de la figura de Ismael en la película Fresa y chocolate está compensada por la presencia de Miguel, un personaje ya presente en Una novia para David (1985) y que volvemos a encontrar en En el cielo con diamantes (2007). La película procede así a una restructuración organizada en un triángulo: el Yo, el Amigo y la Novia en el cual la posición de "Amigo" la ocupan sucesivamente Miguel y Diego y la posición de "Novia" que encarna primero Vivian y luego Nancy. 
El paso del cuento al guión definitivo -que por cierto no se conservó totalmente en la película- es una operación larga y compleja que pone de manifiesto las dificultades del proceso de la adaptación tanto desde el punto de vista del relato y de la narración como de los personajes.

\section{LOS PERSONAJES Y LOS ACTORES}

Por supuesto, si se vuelve a comparar la última versión del guión y la película final se podrán encontrar todavía algunas diferencias secundarias en la narración, pero lo que pertenece ya de hecho a la película son las localizaciones por una parte $y$, sobre todo, la elección de los actores que hacen que un personaje tome cuerpo. En el caso de Fresa y chocolate, y sólo para comprender algunas últimas evoluciones, la dificultad -no del todo resuelta- fue la elección de los actores que tenían que interpretar a Diego y a David. Mientras los casos de Mirta Ibarra (Nancy), Francisco Gattorno (Miguel) y Marilyn Solaya (Vivian) no planteaban mayores problemas, el de Diego, un personaje del que tenían tanto Senel Paz como Tomás Gutiérrez Alea una idea bastante precisa, se mostraba más complejo por cuanto la elección del actor podía determinar el peso del personaje en un relato que, en principio, estaba centrado en David.

... un hombre maduro, de unos cuarenta años, con una cultura asentada por años de estudio y de vivencias en el mundo del arte, no tan atractivo por su físico como por su clase, su personalidad cálida y simpática; pero también un ser indefenso, capaz de motivar sentimientos de compasión (Gutiérrez Alea, 1991, 121).

Esta concepción del personaje se asentaba asimismo sobre una diferencia generacional, repitiendo un modelo que tenía antecedentes literarios y cinematográficos en obras célebres como La confusión de los sentimientos de Stefan Zweig o Muerte en Venecia de Thomas Mann/Luchino Visconti. Desde este punto de vista, la relación entre los dos personajes se sostiene sobre una visión de formación, de educación, e incluso sentimental basada en una diferencia significativa de edad, dado que el personaje de David -cuyo nombre es en si una indicación- tenía unos veinte años. La dificultad para dar con un actor adecuado que se correspondiera con el personaje imaginado por Senel Paz, implicó cambios importantes:

Tuvimos que cambiar nuestra concepción inicial del personaje y nos decidimos por Jorge Perugorría, un actor que podia motivar ciertamente simpatía y compasión, pero que era demasiado joven y atractivo físicamente y no parecía ajustarse fácilmente a la imagen de un hombre maduro y culto (Gutiérrez Alea, 1991,121).

En cierto modo Jorge Perugorría se convirtió prácticamente en lo contrario de lo que se esperaba -basta con comparar su interpretación en Guantanamera para comprenderlo- y tuvo que incorporar elementos, como una nueva gestualidad -que va evolucionando desde el principio al final-, delicada de integrar; una elección que fue objeto de discusión entre el director y el novelista:

Y un día se aparece Titón con la propuesta de Jorge Perugorría... Yo puse el grito en el cielo. Lo había visto actuar en la televisión y el teatro y estaba prejuiciado contra él, porque creía que lo apreciaban más como galán que como actor (García Márquez, 1998, 181).

Las reticencias de Senel Paz mostraban la relevancia de una elección que ponía en tela de juicio el "edificio" del cuento reconsiderando la relación entre los dos personajes protagonistas. Por su parte, la elección del personaje de David presentó más dificultades ya que respondia a la figura de un efebo con una probable ambigüedad física como sugiere este retrato que hace del personaje Tomás Gutiérrez Alea:

De él teníamos también una imagen preconcebida bastante precisa: debía ser muy joven -no más de veinte años- y con los rasgos característicos de un efebo, uno de esos muchachos que de golpe llaman la atención por su atractivo físico en una onda soñadora. Además, debía transmitir una cierta ingenuidad, como de uno que ha llegado recientemente a la ciudad de algún pueblo del interior (Gutiérrez Alea, 1991, 121).

La elección de Jorge Perugorria para Diego ya de por sí rompía el desequilibrio que estaba previsto entre los dos personajes, pero a la hora de buscar un intérprete para

ARBOR Vol. 187748 marzo-abril [2011] 325-335 ISSN: 0210-1963

(n)


David la situación se hizo todavía más complicada como ha dejado escrito Titón en una carta publicada recientemente:

\section{5 de febrero, 1993}

Natalia:

Qué ganas tengo de verte y de disfrutar más tiempo contigo. Ojalá pueda ser muy pronto.

La filmación de la película se volvió a atrasar un par de semanas más porque, después que comencé a ensayar, me tropecé con que el actor principal, el joven que hace el papel de David, iba a quedar muy por debajo de lo que habíamos imaginado. Tuve que cambiarlo con gran dolor de mi alma, porque no hay otro que se acerque tanto al personaje como tipo (personalidad, edad, etc.). Pienso que con ese muchacho hubiera podido lograr el personaje pero que tendria que emplear demasiado tiempo (que no tenemos) y un trabajo intensísimo porque como actor todavía no está maduro. Después de buscar mucho durante los últimos dias, finalmente, encontramos uno que me parece que va a ser muy bueno. Tuvimos que ir a Cienfuegos para hacerle una prueba porque él está ensayando allá una obra y no podía desplazarse hasta La Habana. Dentro de dos o tres días, comenzaremos los ensayos con él. Y no comenzaremos a filmar hasta el 3 de marzo.

Eso quiere decir que, de acuerdo con el plan, debemos terminar el 11 de mayo y probablemente no podré viajar hasta mediados de junio, pues tengo que editar la imagen primero para, después, ir a México a terminar la postfilmación allá. Pero, antes de ir a México trataré de ir a Nueva York para el chequeo médico previsto $y$, por supuesto, pasaré por Miami para verte (Gutiérrez Alea, 2007, 322).

La elección de Vladimir Cruz, por defecto, provocaba un acercamiento todavia mayor entre los dos personajes que terminaron por parecerse cuando el equilibrio inicial exigía que fueran lo más desemejantes posible:

Si Jorge resultaba demasiado joven para ser Diego, Vladimir resultaba demasiado viejo para ser David. En efecto, los dos tenían la misma edad, veintiocho años, por lo que no existía entre ellos la diferencia que nos habiamos planteado al inicio. Además, todo su atractivo se concentraba en sus grandes ojos soñadores. Se trataba no de un efebo sino de un joven cuya belleza no se imponía de golpe; habia que descubrirla poco a poco (Gutiérrez Alea, 2007, 322).

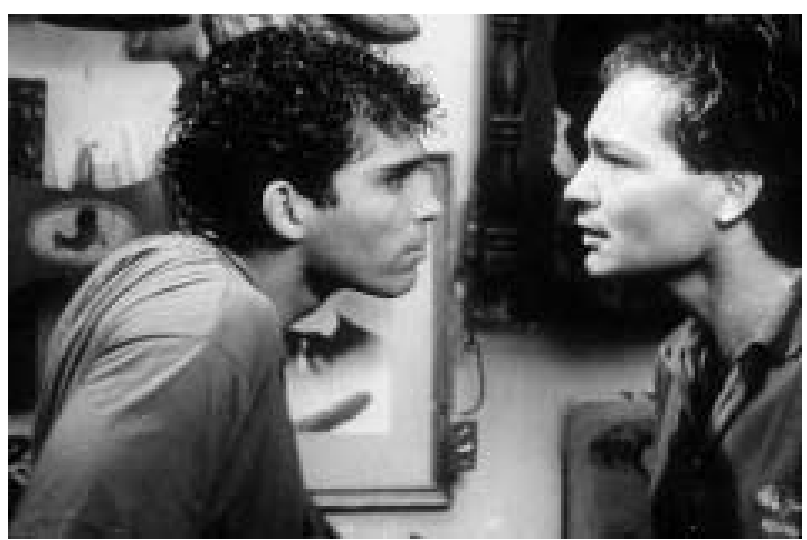

Figura 3. "David y Diego", Tomás Gutiérrez Alea, Fresa y chocolate (1993).

El caso de la elección de los protagonistas en Fresa y chocolate es expresión de uno de los mayores problemas que se plantean en el momento de la adaptación, la "encarnación" del personaje. El personaje literario, incluso en los casos en que el novelista se ha tomado el trabajo de definirlo con detalle, no deja de ser una ficción, una entelequia en el sentido primero de la palabra. El paso de Diego a Diego/Jorge Perugorría, y de David a David/ Vlamidir Cruz -recordemos que existe también el David/ José Luis Álvarez de Una novia para David- es un cambio fundamental en la estructura narrativa de la película e implica una redefinición total aunque para ello no se haya tenido que modificar gran cosa el guión, porque la cuestión de los actores está necesariamente más allá del mismo que sigue siendo, se quiera o no, el último eslabón escrito antes de la visualización del personaje.

\section{¿Éílogo?}

Con El lobo, el bosque y el hombre nuevo, Senel Paz obtuvo en 1991 el Premio Juan Rulfo que otorgan Radio Francia Internacional y el Centro Cultural Mexicano. Fresa y chocolate sigue siendo el mayor éxito del cine cubano, circunstancia que muy probablemente arrastrara al escritor a centrarse en su labor de guionista (Maite, Malena es un nombre de tango, Cosas que dejé en La Habana, Un paraíso bajo las estrellas, Lista de espera, Más vampiros en La Habana, Una rosa de Francia, etc. Su regreso a la literatura se ha hecho recientemente con la publicación de su novela En 
el cielo con diamantes (Ediciones B, 2007), que constituye, en ciertos personajes y situaciones, una prolongación de su célebre cuento, tras un intento fallido en 1996, animado por la invitación de la editora catalana Carmen Balcells como relata en una entrevista:

Me ubicó en un apartamento comodísimo, me regaló una computadora y estuve escribiendo durante seis meses sin preocuparme por nada. Terminé, me devolvi a La Habana con mi computadora, de la que no pude sacar ni una hoja. Nada. Algo le pasó y ahí perdi seis meses de trabajo. En medio de todo me dediqué a hacer guiones de cine, estableciendo compromisos colectivos y abandonando los proyectos personales (Garcia Hernández, 2007).

Esperó de nuevo cuatro años, hasta 2000, para intentar volver a su proyecto literario, pero tampoco lo logró:

Las novelas son periodos de vida que no se pueden interrumpir; una unidad de tiempo, de estado de ánimo y de lenguaje que si se interrumpe, cuando la retomas ya no es una continuación. La reescribi completamente, la terminé este año y tuve la suerte de que Ediciones B de España se interesara en ella. A ver qué pasa, porque es posible que el público me recuerde más como el guionista de Fresa y chocolate que como escritor de literatura (Garcia Hernández, 2007).

Finalmente, En el cielo con diamantes -un recuerdo de la célebre canción de los Beatles, Lucy in the Sky with Diamonds- se publicó en febrero de 2007. La obra es una manera de remontar el tiempo y de explicar el pasado de los personajes del cuento, un pasado que ya desveló, en cierto modo, en Una novia para David. Pero tampoco se puede ignorar que las situaciones, y sobre todo los personajes, han seguido viviendo desde 1981 en las varias adaptaciones teatrales que se hicieron de la obra; así en $L a$ catedral del helado el personaje de Diego fue interpretado por Joel Angelino que desempeñaba el papel de Germán, el homosexual amigo de Diego en Fresa y chocolate y, más recientemente, Damián Albariño y Antonio Arroyo retomaron los papeles de David y Diego.

Con este entramado, que no tiene por qué interrumpirse, el propio Senel Paz no deja de jugar a una recreación infinita, una especie de eterno retorno de los personajes, que se perpetúa en la invitación recogida en las últimas palabras de En el cielo con diamantes:

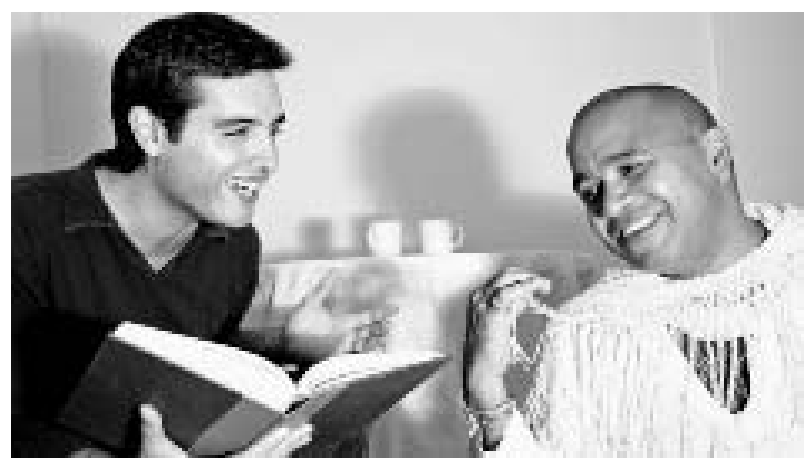

Figura 4. Damián Albariño (David) y Antonio Arroyo (Diego), actores de la última adaptación teatral de Fresa y chocolate (2008).

No sé cuánto tiempo pasó, sólo que seguí escribiendo sin parar, y creo que hubiera escrito todo el novelón de una tirada si no oigo, cuando iba por una parte increible en la que la Virgen de la Caridad se le aparece en la escalera al personaje, una voz acaramelada que me sacó del embeleso. Con permiso, escuché. Hice un gran esfuerzo para regresar a la tierra, a la Isla de Cuba, a La Habana, a la heladería Coppelia, y vi, frente a mí, junto a la silla vacía, a uno de esos tipos que son más mujeres que hombres. Me miraba de una manera tan babosa que sentí como si una vaca me lamiera la cara. No pude resistir la tentación, dijo, me encanta la fresa, $y, \sin$ más, depositó sobre la mesa la bandeja y sus muchas bolsas y paquetes y se sentó. Pero yo, por un instante, viví una alucinación y seguí viéndolo de pie, con la copa de helado en la mano, desdoblado, y disparándome un discurso. Sé que te llamas David, que acabas de encontrar y de perder una ilusión, que tienes un amigo llamado Miguel, y que has comenzado a escribir después de mucho tiempo de esperar por las palabras; ahora el destino, o lo que llamamos destino, me ha puesto frente a ti y habremos de comenzar, tú y yo, una nueva aventura, tan misteriosa y real como la que has vivido. Dicho esto, se sentó y se hizo uno con el otro, y yo pensé, ¿estaré dormido o despierto? (Paz, 2007, 425-426).

Así, desde 1981 hasta 2007, más allá de las obras, de los textos literarios o cinematográficos, las narraciones se han renovado y los personajes han ido adquiriendo su propia independencia para ofrecer un ejemplo, casi único, en el terreno de lo que se suele llamar la "adaptación".

ARBOR Vol. 187748 marzo-abril [2011] 325-335 ISSN: 0210-1963 


\section{ANeXo: esQuema de LOS PERSONAJES EN LAS DIFERENTES OBRAS}

\begin{tabular}{|c|c|c|c|c|c|c|c|c|c|}
\hline & David & Vivian & Diego & Nancy & Miguel & Germán & Ismael & Arnaldo & Ofelia \\
\hline No le digas que la quieres (1981) & Pedrito & Vivian & & & & & & Arnaldo & \\
\hline Una novia para David (1985) & David & & & & Miguel & & & & Ofelia \\
\hline $\begin{array}{l}\text { El lobo, el bosque y el hombre } \\
\text { nuevo (1990) }\end{array}$ & David & Vivian & Diego & & & Germán & Ismael & & \\
\hline Adorables mentiras (1992) & & & & Nancy & & & & & \\
\hline Fresa y chocolate (1993) & David & Vivian & Diego & Nancy & Miguel & Germán & & & \\
\hline
\end{tabular}

\section{NOTAS}

1 La obra ganó, en 1991, el Premio Juan Rulfo otorgado por Radio Francia Internacional y el Centro Cultural Mexicano.

2 El Premio "David" lo otorga la Unión de Escritores y Artistas de Cuba para autores inéditos.

3 Octubre 1967. David Ilega a La Habana para cursar estudios de preuniversitario como becado. Rápidamente hace amistad con Miguel, muchacho despierto y de mayor experiencia en conquistas femeninas. En el aula, la gordita Ofelia, delegada del grupo, no tiene novio y se fija de inmediato en el recién llegado; David, en cambio, se interesa por Olga, admirada por todos los varones. Por otra parte, se va ganando la amistad de Ofelia. Entre los prejuicios, David completa su educación sentimental, enamorándose de Ofelia, una chica más sincera en un entorno más bien frívolo.

Recibido: 14 de octubre de 2008 Aceptado: 30 de marzo de 2009
4 Se trata de Una novia para David (Orlando Rojas, 1985), El amor se acaba (1989) y Adorables mentiras (1992).

5 Como se sabe, si la palabra "maricón" puede tener connotaciones negativas, forma parte del vocabulario reivindicado por la propia comunidad gay como en Estados Unidos se reivindicó la palabra "queer" que designaba despectivamente a los gays.

\section{BIBLIOGRAFÍA}

García Hernández, Arturo (2007): "Arturo García Hernández entrevista a Senel Paz, "Un sobreviviente del éxito", http://www.jornada.unam.mx/2007/ 04/01/sem-arturo.html.

García Márquez, Gabriel (1998): La bendita manía de contar. Taller de guión, Madrid, EICT y Ollero y Ramos.

Gutiérrez Alea, Tomás (1991): "De Fresa y chocolate", Viridiana, n. 7.

- [Titón] (2007): Volver sobre mis pasos, Madrid, Autor SRL. 
Paz, Senel (2007): En el cielo con diamantes, Barcelona, Ediciones B.

Santana, Gilda (1994): "Fresa y chocolate, el largo camino de la literatura al cine", Viridiana, n. 7, pp. 131140.

Valdés Lizano, Miguel Ángel (2007): "Senel Paz: en la madriguera del anonimato",
http://www.escambray.cu/Esp/Cultura/ Psenelpaz0604271142.htm. 